\title{
Reports of Two Broken Nexplanon® Rods
}

\author{
Joanna Campodonico, MD, MPH, Jeffrey Wolfrey, MD, and Jenna Buchanan, MD
}

Damage to progestin containing contraceptive implants has been reported for Implanon $₫$ rods but there appear to be few reports of damage to Nexplanon ${ }^{\circledR}$ rods. This report describes 2 cases of Nexplanon ${ }^{\circledR}$ rod breakage in an 18 -year-old female and a 25 -year-old female. The literature regarding damaged progestin implants is reviewed. These reports often involve an alteration in menstrual bleeding pattern and patients frequently request removal of bent or broken implants. The overall incidence of rod breakage and impact of damaged implants on contraceptive efficacy is not clear. Evidence based guidelines to inform management of suspected damage to contraceptive implants would be helpful. In the meantime, a shared decision-making process offering removal and replacement of damaged implants would seem reasonable. (J Am Board Fam Med 2019;32:269-271.)

Keywords: Contraception, Contraceptive Devices, Progestins

\section{Case Histories}

This report will describe 2 cases of damaged Nexplanon ${ }^{\circledR}$ rods. In the first case, an 18-year-old female with an unremarkable history presented for Nexplanon removal. The rod had been placed 8 months earlier. The patient sustained local blunt trauma to the implant during a softball game. She subsequently noticed that the device was bent. Several weeks later, the patient experienced vaginal bleeding resembling a normal period. This was the first vaginal bleeding she had noted following the Nexplanon insertion aside from light spotting. The Nexplanon was readily palpated, but it was centrally concave on examination with the 2 opposite ends tenting at the skin surface when pressed in the center (please see Figure 1). The patient opted for removal and reinsertion through a shared decision-making process. The Nexplanon was removed according to manufacturer guidelines. A urine pregnancy test on the day of removal was negative. The Nexplanon rod was noted to have broken at the midpoint of the

This article was externally peer reviewed.

Submitted 1 August 2018; revised 24 October 2018; accepted 25 October 2018.

From University of Arizona College of Medicine Phoenix, Phoenix, AZ.

Funding: none.

Conflict of interest: none declared.

Corresponding author: Joanna Campodonico, MD, MPH, University of Arizona College of Medicine, Phoenix, AZ 85014 (E-mail: jcampodo85@gmail.com).
Figure 1. Damaged Nexplanon $\circledR_{\text {removed from case } 1 .}$

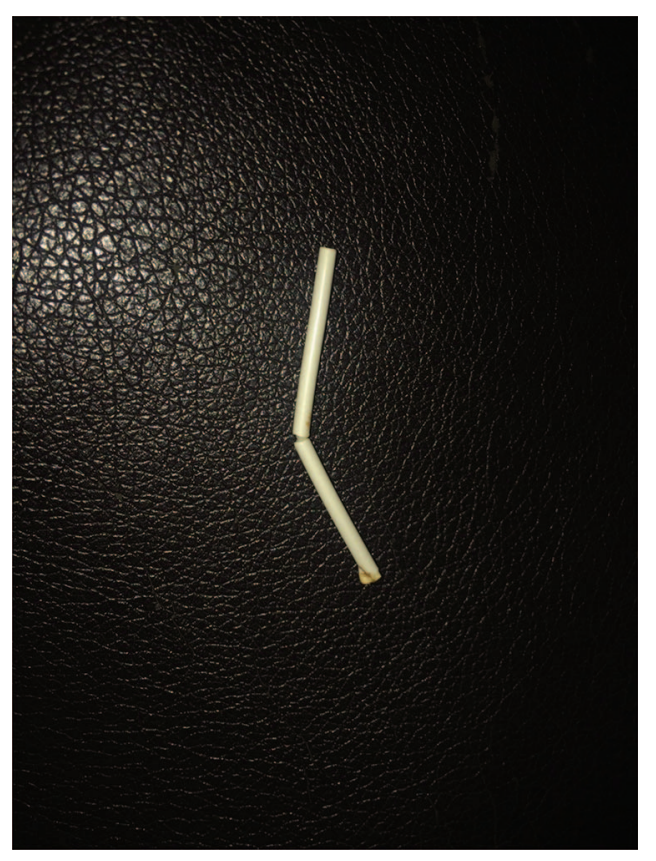

device. A new Nexplanon was then inserted at the same site. The procedure was tolerated well without complications. The incident was reported to Merck by telephone (1-866-342-5683).

In the second case, a 25 year-old female with a history of morbid obesity presented to her community health clinic for Nexplanon removal. The rod had been placed 18 months earlier. She reported lifting heavy objects greater than 50 pounds 1 month 
before presentation. She subsequently noticed the rod appeared to have an irregular shape on palpation. She experienced 2 menstrual periods over the subsequent month after having been amenorrhoeic since the rod had been placed. She was initially evaluated and was advised the rod was bent. She continued to experience intermenstrual bleeding and returned for Nexplanon removal. The Nexplanon was palpated and noted to have 2 discrete, nonconjoined segments. The Nexplanon was removed according to manufacturer guidelines. A urine pregnancy test on the day of removal was negative. The Nexplanon rod was noted to have broken distal to the midpoint of the device. A new Nexplanon was then inserted in the contralateral arm. The procedure was tolerated well without complications. The incident was reported to Merck by telephone (1-866-342-5683).

\section{Background}

A literature search using PubMed was conducted using terms such as "broken, fractured, or damaged" Nexplanon. Only 8 articles were available that described a clinical scenario similar to the one experienced by our patients. Elliman ${ }^{1}$ reported the occurrence of a fractured Nexplanon implant in which the removed rod was noted to have a breach in the convex surface of the rod. This was noted to have occurred without known trauma. Bentley ${ }^{2}$, in response to Elliman, similarly describes the removal of damaged implants from 7 patients, 6 of which were Nexplanon implants. In 1 report, 2 episodes of breakage of an Implanon ${ }^{\circledR}$ rod in a family planning clinic were described. In this report, 1 of the rods was noted to have separated into 2 pieces without trauma, while the other rod broke into 2 pieces after the arm was grabbed forcefully. ${ }^{3}$ This article cites unpublished data from Merck indicating that the release rate of etonogestrel may be altered by rod breakage. ${ }^{3}$ This source stated that during development the implants were purposely damaged to determine the effect on hormone release. In response to the article from Elliman, Rekers ${ }^{4}$, a Merck employee, references the same unpublished Merck data of in vitro release of etonogestrel in damaged implants. In vitro release of etonogestrel from the damaged implant was reported to be slightly increased compared with hormone release from undamaged implants. The author states that the release of etonogestrel from a fractured implant is essentially unchanged as the core content and surface area of the implant skin have not been altered in a damaged implant. ${ }^{4}$ Rekers does not address the issue of whether damage to the implant skin affects the rate of etonogestrel release.

Altered progestin release could potentially change a patient's bleeding pattern as noted by Agrawal and Robinson ${ }^{5}$ in their report of spontaneous snapping of an Implanon rod. The package insert notes that "when an implant is broken or bent, the release rate of etonogestrel may be slightly increased". ${ }^{6}$ Pickard and Bacon ${ }^{4}$ posit that it is possible that contraceptive effectiveness could be diminished by rod breakage, although no studies have tested that hypothesis. Three case reports describe patients with broken Implanon rods associated with a change in vaginal bleeding pattern. $5,7,8$

\section{Discussion}

This case report describes 2 patients with a broken Nexplanon rod. This has been reported with Implanon rods but this seems to be one of the first case reports associated with the Nexplanon system. The clinical implications and optimal management of damaged progestin implants remains unclear. There is no clear guideline for confirming suspicion of damage to an implanted rod. There are many studies assessing ultrasound as a modality to find nonpalpable progestin implants but not to determine if one is bent or broken. ${ }^{9}$ There may be a role for $\mathrm{x}$-rays in assessing placement and structural integrity of an implant. However, this modality has only been studied as a means to locate nonpalpable implants. ${ }^{10,11}$ Implanon and Nexplanon are bioequivalent but the addition of $3 \%$ barium in Nexplanon confers the radiopaque quality. There are no published studies describing the incidence of damaged implants or comparing the incidence of damaged implants with and without the addition of barium.

The cases reported here do involve a change from a previous pattern of menstrual bleeding, suggesting a fluctuation in hormone delivery. Tomás-Tello and Hodgson ${ }^{8}$ suggest a blood test to assess the hypothesis of altered release of etonogestrel from a damaged unit, but there is no evidence to support this practice. ${ }^{8}$ Studies to measure the impact of damage to implants on serum progestin levels and the levels needed to maintain active contraception could help guide management. There is a dearth of information to inform management of damaged or bent Nexplanon rods. The case reports of damaged im- 
plants indicate that many patients wish to have them removed. The approach with these patients was based on theoretical risk and shared decision-making. Future studies to support the creation of evidence-based guidelines regarding management of suspected Nexplanon rod damage would be welcome. In the meantime, a shared decision-making process offering the option of removal and replacement would seem reasonable when damage to an implant is suspected.

To see this article online, please go to: http://jabfm.org/content/ 32/2/269.full.

\section{References}

1. Elliman A. Removal of a fractured Nexplanon ${ }^{\circledR}$. J Fam Plann Reprod Health Care 2013;39:66-7.

2. Bentley J. Experience and removal of damaged implants. J Fam Plann Reprod Health Care 2013; 39:233.

3. Torres R, Mendes N, Machado AI, Marques. In situ breakage of Implanon ${ }^{\circledR}$ - two cases of a rare occurrence. Contraception. 2013;189-91.
4. Rekers H. Removal of a fractured Nexplanon ${ }^{\circledR}$ : MSD response. J Fam Plann Reprod Health Care 2013;39:67.

5. Agrawal A, Robinson C. Spontaneous snapping of an Implanon ${ }^{\circledR}$ in two halves in situ. J Fam Plann Reprod Health Care 2003;29:238.

6. Merck. Nexplanon ${ }^{\circledR}$ packing insert. Whitehouse Station, NJ: Merck. Published 2011-2017.

7. Pickard S, Bacon L. Persistent vaginal bleeding in a patient with a broken Implanon $®$. J Fam Plann Reprod Health Care 2002;28:207-8.

8. Tomás-Tello MD, Hodgson G. Two cases of broken Implanon ${ }^{\circledR}$. J Fam Plann Reprod Health Care. 2010;36:255.

9. Shulman LP, Gabriel H. Management and localization strategies for the nonpalpable Implanon ${ }^{\circledR}$ rod. Contraception 2006;73:325-30.

10. Doshi J. Bent Implanon ${ }^{\circledR}$. J Fam Plann Reprod Health Care 2011;37:126.

11. Mommers E, Blum GF, Gent TG, Peters KP, Sordal TS, Marintcheva-Petrova M. Nexplanon ${ }^{\circledR}$, a radiopaque etonogestrel implant in combination with a next-generation applicator: 3 -year results of a noncomparative multicentral trial. Am J Obstet Gynecol. 2012;207:388.e1-6. 